\section{Regional conference on conservation of animal genetic resources}

A regional conference on genetic resources was held in Muscat, Oman, during 23-25 February 2016, with the theme 'Towards sustainable utilization of genetic materials'. The conference was hosted at Sultan Qaboos University under the patronage of his excellency Dr Saud Al Bimani, Vice Chancellor, and his excellency Dr Hilal bin Ali AlHinai, Secretary General of the Oman Research Council. The conference was organized and funded by the Oman Animal and Plant Genetic Resource Centre, in partnership with the University and the Ministry of Agriculture and Fisheries Wealth. The event brought 139 participants from 18 countries (Oman, Kuwait, Egypt, Iraq, Yemen, UAE, France, Italy, Sierra Leone, Nigeria, Algeria, Sweden, Ethiopia, Sudan, Malaysia, Saudi Arabia, Kazakhstan and Portugal). There were 19 oral presentations, including four invited speakers, from Sweden, Portugal, France and Kazakhstan, and 25 poster presentations.

The goal of the conference was to complement other conferences in the region that have highlighted the importance of conserving the biodiversity of the Arabian Peninsula. Additionally, the conference was designed to expand the cooperation of participants with neighbouring countries and international bodies, and to provide information and analyses on the status and trends of threatened species. The conference highlighted the creation of the first genetic resource centre in Oman. Design and construction of the Centre's laboratories and holding facilities is underway, and the administrative offices and technical staff premises are complete. Samples from live and recently deceased animals have been cryopreserved at the Department of Biology at Sultan Qaboos University, including reproductive tissues, germplasm cells and somatic cells from threatened species such as the Arabian leopard Panthera pardus nimr, tahr Hemitragus jayakari, gazelle Gazella gazella, caracal Caracal caracal and the Arabian oryx Oryx leucoryx.

The themes of the conference were genetics, genomics, reproduction, animal diseases, conservation of wild animals and genetic improvement. The reproduction theme included talks about biobanking of reproductive cells from threatened animals, and modern techniques for conservation and maintaining germplasm banks. The genetics theme included talks on livestock breeds and conservation plans, and on genome-wide characterization at a global scale.

The conference emphasized the importance and challenges that influence genetic resource banking of native species. Conference participants agreed to address knowledge gaps and strengthen research outcomes, enhance the relationship between research and field programmes, and establish international coordination networks. It is anticipated that the Oman Animal and Plant Genetic Resource Centre will hold this conference biennially.

SENAN BAQIR Department of Biology, College of Science, Sultan Qaboos University, Muscat, Oman

E-mail baqirs@yahoo.com

Duaa Al Moqbali, Asila Al Naabi and Nadiya Al SaAdy Oman Animal and Plant Genetic Resource Center, Muscat, Oman 